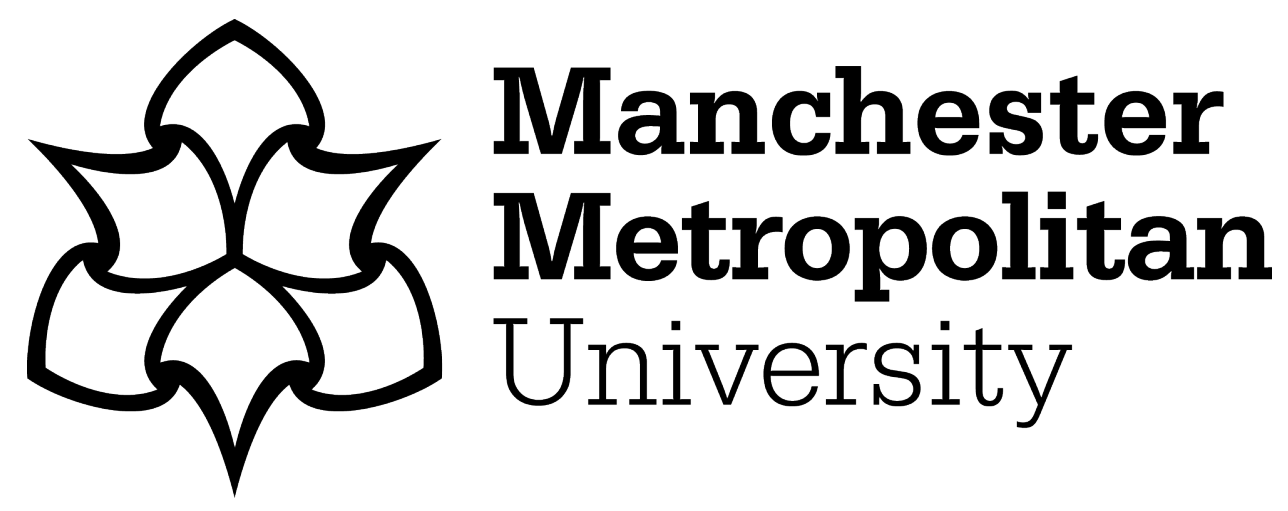

Naderi, A, Baloochi, R, Rostami, KD, Fourchet, F and Degens, H ORCID logoORCID: https://orcid.org/0000-0001-7399-4841 (2020) Obesity and foot muscle strength are associated with high dynamic plantar pressure during running. The Foot, 44. p. 101683. ISSN 0958-2592

Downloaded from: https://e-space.mmu.ac.uk/626376/

Version: Accepted Version

Publisher: Elsevier

DOI: https://doi.org/10.1016/j.foot.2020.101683

Please cite the published version 
Original Article

\title{
Obesity and foot muscle strength are associated with high dynamic plantar pressure during running
}

\author{
Aynollah Naderi $^{\mathrm{a}, *}$, Ramin Baloochi ${ }^{\mathrm{b}}$, Komeil Dashti Rostami ${ }^{\mathrm{c}}$, François Fourchet ${ }^{\mathrm{d}}$, \\ Hans Degens ${ }^{\mathrm{e}, \mathrm{f}, \mathrm{g}}$ \\ a Department of Health and Corrective Exercise, School of Physical Education and Sport Sciences, Shahrood University of Technology, Shahrood, Semnan, Iran \\ ${ }^{\mathrm{b}}$ Department of Health and Corrective Exercise, School of Physical Education and Sport Sciences, Allameh Tabataba'i University, Tehran, Iran \\ ${ }^{\mathrm{c}}$ Department of Biomechanics, Faculty of Physical Education and Sports Sciences, University of Mazandaran, Mazandaran, Babolsar, Iran \\ ${ }^{\mathrm{d}}$ Motion Analysis Lab, Physiotherapy Department, La Tour Hospital, Meyrin, Switzerland \\ ${ }^{\mathrm{e}}$ Department of Life Sciences, Manchester Metropolitan University, UK \\ ${ }_{\mathrm{f}}^{\mathrm{f}}$ Institute of Sport Science and Innovations, Lithuanian Sports University, Lithuania \\ ${ }^{\mathrm{g}}$ University of Medicine and Pharmacy of Targu Mures, Romania
}

\section{A R T I C L E I N F O}

Keywords:

Body mass index

Recreational runners

Lower extremity overuse injuries

Foot muscle strength

Endurance

\begin{abstract}
A B S T R A C T
Obese people are often encouraged to lose body mass by exercise. The aim of the study was to determine the effect of body mass and ankle muscle strength on the dynamic foot-pressure distribution before and after running. Twenty-five normal weight $(72.0 \pm 5.3 \mathrm{~kg}), 25$ overweight $(80.8 \pm 5.6 \mathrm{~kg})$ and 25 obese $(96.8 \pm 6.5 \mathrm{~kg})$ age- and height-matched male recreational runners joined the study. Before and after $30 \mathrm{~min}$ running, dynamic foot-pressure distribution during running, and ankle plantarflexor, dorsiflexor, invertor and evertor muscle strength were measured using a foot-scan pressure-plate and isokinetic dynamometer, respectively. Body mass index and percentage fat mass correlated positively to almost all components of foot-pressure distribution; this explantion was extracted from $14 \%$ (for toe 1) to $52 \%$ (for dynamic arch index) of peak foot pressure and between $21 \%$ (for metatarsal 1) to $48 \%$ (for midfoot) of the impulse underneath different foot zones. Only plantarflexor muscle strength significantly predicted plantar pressure and impulse underneath the $\mathrm{T} 1, \mathrm{~T} 2-5$, midfoot area and the dynamic arch index. After running, plantarflexor and invertor muscle strength predicted from $30 \%$ (for metatarsal 2) to $58 \%$ (for metatarsal 1) of peak foot-pressure and impulse underneath the different foot zones. Obesity is associated with excessive plantar loading that is aggravated after running by fatigue-related reductions in plantar flexor and invertor muscle strength. To prevent foot pain and injuries related to excessive foot pressures, at the start of the weight control process non-weight bearing rather than weight-bearing exercise is advisable.
\end{abstract}

\section{Introduction}

The prevalence of obesity has reached epidemic proportions and is a growing health concern [1]. Indeed, obesity is a significant risk factor for the development of many health problems, such as dyslipidemia, high blood pressure, type II diabetes [2], and less often realized, orthopedic problems due to overload of musculoskeletal structures, especially in the lower extremities [3].

Running is one of the most popular types of exercise that contributes to health and fitness, and has gained considerable popularity over the past three decades due to easy access and overall promotion of sport [4]. As running is an efficient way to burn calories, many overweight and obese people are encouraged to lose weight by running [5].

Previous studies have shown that proper function of foot muscles, especially intrinsic and extrinsic arch-support muscles, are essential for pronation control [6] and the absorption of impacts [7,8], thereby protecting the foot, lower leg and spinal column against repetitive trauma during walking and running [9]. Therefore, weakness and dysfunction of foot muscles can put people at risk of overuse injuries related to excessive pronation [10].

Overpronation occurs when an individual moves too far through the phases of foot pronation, causing the foot to have a larger support surface than that required [11]. In our study, the focus was on the midfoot/arch behavior during the stance phase of running by dividing


Shahrood, Semnan, Iran.

E-mail address: ay.naderi@shahroodut.ac.ir (A. Naderi). 
the contact area of the midfoot to the total contact area to calculate the dynamic arch index (DAI) as an indication of the arch height. A large DAI represents a low arch (reflecting excessive pronation), while a small DAI represents a high arch (reflecting excessive supination) [12].

In the clinic, excessive static or dynamic foot pronation is considered a risk factor for injury. Dynamic foot pronation can be measured by motion-analysis systems that is not everywhere available. Static foot postureis more commonly measured in the clinic by methods such as navicular drop tests and foot posture index (FPI-6), but static foot pronation measures cannot be extrapolated to dynamic foot pronation [13]. The DAI, the ratio of the mid-foot contact area relative to the total foot contact area during mid-stance phase of gait, has been used in previous studies as a measure of foot dynamics during gait $[14,15]$, and has high reliability of foot classification $($ ICC $=0.99$ ) [16].

Repetitive contractile activity, such as during running, induces muscle fatigue characterized by a reduction in the force-generating capacity and slowing of the muscle [17,18]. Muscle fatigue of the foot and ankle muscles during running is associated with changes in foot roll-over and ankle movement kinematics $[7,17]$ that will lead to suboptimal running mechanics [19]. Indeed, it has been observed that foot muscle fatigue shifted the dynamic plantar pressure to the medial forefoot (MF) [7,8], reflecting excessive pronation. Foot fatigue was defined as a reduced ability of, in this case, the foot muscles to develop the required force during continued contractile activity [20]. The excessive pronation increases the risk of running-related injury, such as medial tibial stress syndrome, due to the accumulation of microtrauma arising from repetitive undue loading of tendons, muscles and bones $[19,21,22]$.

In obese and overweight people, perhaps more important than the development of muscle fatigue is how their high body mass has been reported to affect plantar pressure pattern [23], walking strategies [24] and foot posture [25,26], such that they were at a higher risk of foot discomfort and/or pathologies than normal-weight people [3,9].

To our knowledge, no study has investigated the impact of body mass, muscle strength and muscle fatigue on the dynamic plantarpressure distribution and dynamic foot posture in recreational runners before and following prolonged running. Therefore, the aim of the present study was to assess the impact of obesity and lower leg muscle strength on the dynamic plantar-pressure distribution in recreational runners before and following a run. It was hypothesized that obesity is associated with higher dynamic plantar-pressure and altered pressure distributions that are aggravated by lower leg muscle strength and become worse after running due to the development of muscle fatigue.

\section{Methods}

\subsection{Study Design}

This study was a cross-sectional, case-control design that examined individuals with different body mass matched for age and height. The study was performed in a sports science laboratory of Shahrood University of Technology. All procedures were approved by the Institutional Review Board of Shahrood University of Technology and were in accordance with the Declaration of Helsinki.

\subsection{Participants}

Sample size calculations were based on $\mathrm{R}^{2}$ for the correlation between body mass and peak plantar-pressure in previous studies [24], using the software package $G *$ Power3.1. With an $R^{2}$ of 0.32 attributed to body mass and the desired power (1- $\beta$ ) of 0.80 , using an F-Test with a 2-tailed significance level $(\alpha)$ of 0.05 a total sample size of 73 was needed.

Seventy-five m en who participated in recreational running joined the study. The body mass index (BMI) was calculated as body mass in kilograms divided by height in meters squared $\left(\mathrm{kg} \cdot \mathrm{m}^{-2}\right)$ and participants were classified as normal weight (BMI $18.5-24.9 \mathrm{~kg} \cdot \mathrm{m}^{-2}$ ), overweight (BMI $25-29.9 \mathrm{~kg} \cdot \mathrm{m}^{-2}$ ) and obese $\left(\mathrm{BMI} \geq 30 \mathrm{~kg} \cdot \mathrm{m}^{-2}\right)^{2}$. Each group consisted of 25 people: normal weight, overweight and obese. Inclusion criteria were: age 20 to 40 years; BMI 18.5 to $45 \mathrm{~kg} \cdot \mathrm{m}^{-2}$; ability to complete the 30 -min run; no foot pain after completion of the 30-min run; no participation in other exercise programs or sport, other than running. Participants were excluded if they had current back, hip, knee, or foot pain; significant foot malalignments; lower extremity injury or surgery in the last 6 years; leg-length discrepancy; use of foot orthoses; uncontrolled hypertension (defined as a blood pressure $>$ $180 / 100 \mathrm{mmHg}$ ); diabetes-related peripheral neuropathy.

All participants lived in Shahrood and were recruited through presentations in the local community between June and December 2017. All participants were informed of the study procedures and signed an informed consent form.

\subsection{Procedure}

Participants returned three times to the laboratory. During registration, participant basic demographics and anthropometric data (such as body mass, heightand BMI) were collected.

Five to 7 days prior to the first measurement session, a familiarization session was conducted to introduce the experimental procedures to the participants. In this session, we explained and demonstrated the testing protocol.

A week after the familiarization session, the dynamic plantar pressure distribution, dynamic foot posture, and isokinetic muscle strength and endurance of ankle muscles were measured. The dynamic plantar pressure distribution and dynamic foot posture were measured before and immediately after $30 \mathrm{~min}$ of outdoor running. During the foot-scan pressure trials, the participants wore the running shoes they used for recreational running and run at a speed of $3.3 \mathrm{~m} \cdot \mathrm{s}^{-1} \pm 5 \%$ over a runway [27]. The speed was monitored by two sets of infrared photocells. Each participant performed 3 left and 3 right stances to assess the dynamic plantar pressure distribution during standing, and 2 sets of 6 contractions in concentric and eccentric modes for isokinetic testing.

\subsection{Measurements}

\subsubsection{Anthropometric measurements}

Body mass was measured on a digital scale (model SECA 225, Vogel \& Halke GmbH \& Co., Hamburg, Germany) to the nearest $0.1 \mathrm{~kg}$ and height was measured using a stadiometer (model SECA 760, Vogel \& Halke GmbH \& Co., Hamburg, Germany) to the nearest $0.1 \mathrm{~cm}$ with participants in underwear and barefoot. Body fat percent (BFP) was estimated with bioelectrical impedance (TANITA BC-418, Tanita, Tokyo, Japan) and the waist to hip ratio (WHR) calculated.

\subsubsection{Dynamic plantar pressure distribution}

The dynamic plantar pressure distribution during running trials was assessed using a foot-scan pressure-plate (RsScan International, Belgium, $40 \times 100 \mathrm{~cm}, 8192$ sensors, $253 \mathrm{~Hz}$ ) that was placed in the middle of a 12-m-long runway. Participants were asked to run at a speed of $3.3 \mathrm{~m} \cdot \mathrm{s}^{-1} \pm 5 \%$ over the $12-\mathrm{m}$ runway. Three valid left and three valid right stance phases were recorded before and after $30 \mathrm{~min}$ of running. Trials were considered valid if the participant had a heel strike pattern, complete foot contact and made no adjustment in step length to make contact with the pressure plate. The reliability of the RSscan system for the temporal plantar pressure variables of foot roll-over during running have been previously reported (ICC.0.75) [27].

The software (Footscan1 software 7.0 Gait 2nd Generation, RsScan International) automatically divided the foot into ten anatomical zones that were manually controlled and adapted (if necessary) by the researcher: medial heel (HM), lateral heel (HL), midfoot (MF), metatarsal areas I-V (M1, M2, M3, M4, and M5), the hallux (T1) and foot toes 2-5 
(T2-5) $[21,27]$.

For those regions, temporal data (i.e. moment the regions made contact and moments of loss of contact), peak pressure data and absolute impulse were calculated from duration of each phase and pressure during the phase by the RScan software [21].

Five distinct instants of foot rollover were determined to divide the stance period into four phases: first foot contact (FFC: the instant the foot made first contact with the pressure plate), first metatarsal contact (FMC: the instant one of the metatarsal heads contacted the pressure plate), forefoot flat (FFF: the first instant all metatarsal heads made contact with the pressure plate), heel off (HO: the instant the heel loses contact with the pressure plate) and last foot contact (LFC: the last contact of the foot on the plate). Based on these instants, total foot contact time (TCT) was divided into four phases: initial contact phase (ICP: FFC $\rightarrow$ FMC), forefoot contact phase (FFCP: FMC $\rightarrow$ FFF), foot flat phase (FFP: FFF $\rightarrow$ HO) and forefoot push-off phase (FFPOP: HO $\rightarrow$ LFC) $[21,27]$.

Medio-lateral pressure ratios $((\mathrm{T} 1+\mathrm{M} 1+\mathrm{HM})-(\mathrm{HL}+\mathrm{M} 3+$ $\mathrm{M} 4+\mathrm{M} 5) /(\mathrm{T} 1+\mathrm{M} 1+\mathrm{M} 3+\mathrm{M} 4+\mathrm{M} 5+\mathrm{HM}+\mathrm{HL}))$ were calculated at these five instants of foot contact. The mean of this ratio was calculated for each phase (ICP, FFCP, FFP, and FFPOP). The mean of three trails was taken for analysis [21,27].

\subsubsection{Dynamic foot posture}

Dynamic arch structure, evaluated by the DAI, is correlated with MF contact area [28]. A high DAI ratio indicates higher foot pronation; $<0.21$ high arch, 0.21-0.28 normal arch and $>0.28$ low arch [29].

\subsubsection{Isokinetic muscle strength and endurance}

A Biodex System 3 Pro Dynamometer (Biodex Medical Systems, Inc., Shirley, NY) was used to assess the strength and endurance of the ankle plantarflexor, dorsiflexor, invertor and evertor muscles. An isokinetic dynamometer is a reliable instrument to measure the torque around the ankle joint [30]. Before the isokinetic evaluation, the participants performed a 5-min warm-up, including walking on the treadmill at their own speed, and performed 3 3-s muscle stretches for each ankle muscle group. The isokinetic dynamometer was calibrated and positioned for optimal recording. The participants then sat on the Biodex machine to establish the maximum range of motion for each test condition. A gravity correction was performed by the Biodex software before testing each subject.

To perform the ankle plantarflexor and dorsiflexor muscle testing, participants sat on the adjustable seat of the dynamometer, with a hip flexion of $70-85^{\circ}$ and knee flexion of $20-30^{\circ}$. For invertor and evertor muscle testing the hip flexion was $90^{\circ}$ and knee flexion $35-40^{\circ}$. The torso, back, and thigh were stabilized in place by straps. The ankle was also retained on a footplate, with the heel supported in a rubber heel cup at $90^{\circ}$ and the forefoot secured by two Velcro straps. The test foot was positioned so that the ankle rotation axis aligned with the dynamometer rotation axis. Participants were instructed to hold onto the lateral support (arms) of the chair to improve stability. Prior to the procedure, verbal explanation was provided for each test, and participants were asked to perform three specific submaximal contractions to familiarize themselves with each testing procedure.

Both right and left limbs were tested at $60^{\circ} \cdot \mathrm{s}^{-1}$ and $120^{\circ} \cdot \mathrm{s}^{-1}$ with constant verbal encouragement to help the participants maintain maximum strength during contractions. The test consisted of a set of five repetitions at $60^{\circ} \cdot \mathrm{s}^{-1}$ and another set of 20 repetitions at $120^{\circ} \cdot \mathrm{s}^{-1}$ [31] in the concentric mode. Each repetition was separated by $30 \mathrm{~s}$ rest, and between each muscle evaluation, there was 15 min rest. In all participants, the right or left limb was randomly tested first and in all cases, measurements started at the lower speed.

Isokinetic measurements that were utilized for statistical analysis included: absolute peak torque at $60^{\circ} \cdot \mathrm{s}^{-1}(\mathrm{~N} \cdot \mathrm{m})$, defined as the maximum torque obtained for the series of five repetitions and endurance (total work done in five last repetitions compared to that in the first five repetitions) of $120^{\circ} \cdot \mathrm{s}^{-1}$ (in \%) [32, 33]. Isokinetic peak torques normalized to body mass $\left(\mathrm{N} \cdot \mathrm{m} \cdot \mathrm{kg}^{-1}\right)$ were also reported.

\subsection{Statistical analysis}

SPSS software (version 18.0, SPSS Inc., Chicago, IL, USA) was used for statistical analyses. The Shapiro-Wilk test was used to assess normality. A 3 (groups: normal weight, overweight, and obesity) $\times 2$ (times: baseline, after 30 min running) repeated-measures ANOVA was used to test the main and interaction effects of body mass and prolonged running on dynamic plantar pressure distribution. If a main group effect was found, additional between-group comparisons (multiple comparisons) were conducted using Tukey's HSD tests. Data are presented as mean \pm SD and the significance level was set at $\mathrm{p} \leq .05$.

Stepwise regression was conducted to identify which foot muscle strength and endurance, and obesity-related components are the strongest indicators of the dynamic plantar-pressure distribution.

\section{Results}

The anthropometric data of the three groups are presented in Table 1. There were no significant differences between groups with respect to age and height, sessions, duration, and distance run per week,

Table 1

Participant characteristics and total contact time.

\begin{tabular}{|c|c|c|c|c|c|c|}
\hline \multicolumn{2}{|l|}{ Variables } & $\begin{array}{l}\text { Normal weight }(\mathrm{n}=25) \\
\text { Mean } \pm \text { SD }\end{array}$ & $\begin{array}{l}\text { Over weight }(n=25) \\
\text { Mean } \pm S D\end{array}$ & $\begin{array}{l}\text { Obesity }(n=25) \\
\text { Mean } \pm S D\end{array}$ & $\mathrm{~F}$ & p-value \\
\hline \multicolumn{2}{|l|}{ Age (y) } & $27.9 \pm 2.8$ & $28.6 \pm 2.4$ & $29.1 \pm 2.7$ & 1.0 & 0.4 \\
\hline \multicolumn{2}{|l|}{ Mass $(\mathrm{kg})$} & $72.0 \pm 5.3$ & $80.8 \pm 5.6^{\mathrm{a}}$ & $96.8 \pm 6.5^{\mathrm{a}, \mathrm{b}}$ & 95 & 0.001 \\
\hline \multicolumn{2}{|l|}{ Height $(\mathrm{cm})$} & $180 \pm 8.4$ & $177 \pm 5.2$ & $175 \pm 4.1$ & 3.1 & 0.06 \\
\hline \multicolumn{2}{|l|}{ Body fat percent (\%) } & $15.6 \pm 1.3$ & $22.5 \pm 2.1^{\mathrm{a}}$ & $27.9 \pm 1.9^{\mathrm{a}, \mathrm{b}}$ & 243 & 0.001 \\
\hline \multicolumn{2}{|l|}{ Body mass index $\left(\mathrm{kg} \cdot \mathrm{m}^{-2}\right)$} & $22.3 \pm 1.3$ & $25.9 \pm 0.7^{\mathrm{a}}$ & $31.5 \pm 1.5^{\mathrm{a}, \mathrm{b}}$ & 295 & 0.001 \\
\hline \multicolumn{2}{|l|}{ Waist hip ratio (\%) } & $85.1 \pm 1.5$ & $94.1 \pm 2.1^{\mathrm{a}}$ & $101.0 \pm 2.8^{\mathrm{a}, \mathrm{b}}$ & 257 & 0.001 \\
\hline \multicolumn{2}{|c|}{ Number of running sessions per week } & $3.5 \pm 0.6$ & $3.4 \pm 0.8$ & $3.7 \pm 0.7$ & 1.4 & 0.3 \\
\hline \multicolumn{2}{|c|}{ Minutes run per week } & $95.3 \pm 17.9$ & $91.8 \pm 19.9$ & $81.5 \pm 18.9$ & 2.8 & 0.07 \\
\hline \multicolumn{2}{|l|}{ Distance run per week $(\mathrm{km})$} & $12.1 \pm 3.5$ & $12.8 \pm 3.1$ & $11.5 \pm 2.7$ & 0.8 & 0.5 \\
\hline \multirow[t]{2}{*}{ DAI (\%) } & Before & $23.6 \pm 2.3$ & $24.8 \pm 2.4$ & $25.7 \pm 2.6^{\mathrm{a}}$ & 4.2 & 0.02 \\
\hline & After & $24.1 \pm 2.4$ & $25.7 \pm 2.7$ & $27.1 \pm 2.9^{\mathrm{a}, \mathrm{b}, \mathrm{c}}$ & 6.8 & 0.01 \\
\hline \multirow[t]{3}{*}{ Total foot contact time (ms) } & Before & $218 \pm 25$ & $238 \pm 26$ & $245 \pm 30^{\mathrm{a}, \mathrm{c}}$ & 5.3 & 0.01 \\
\hline & After & $242 \pm 22^{c}$ & $260 \pm 31^{c}$ & $287 \pm 31^{\mathrm{a}, \mathrm{b}, \mathrm{c}}$ & 14.6 & 0.001 \\
\hline & Delta & 24 & 22 & 42 & & \\
\hline
\end{tabular}

\footnotetext{
a indicates significant difference from normal group.

b indicates differences from overweight group.

c different from before.
} 
A
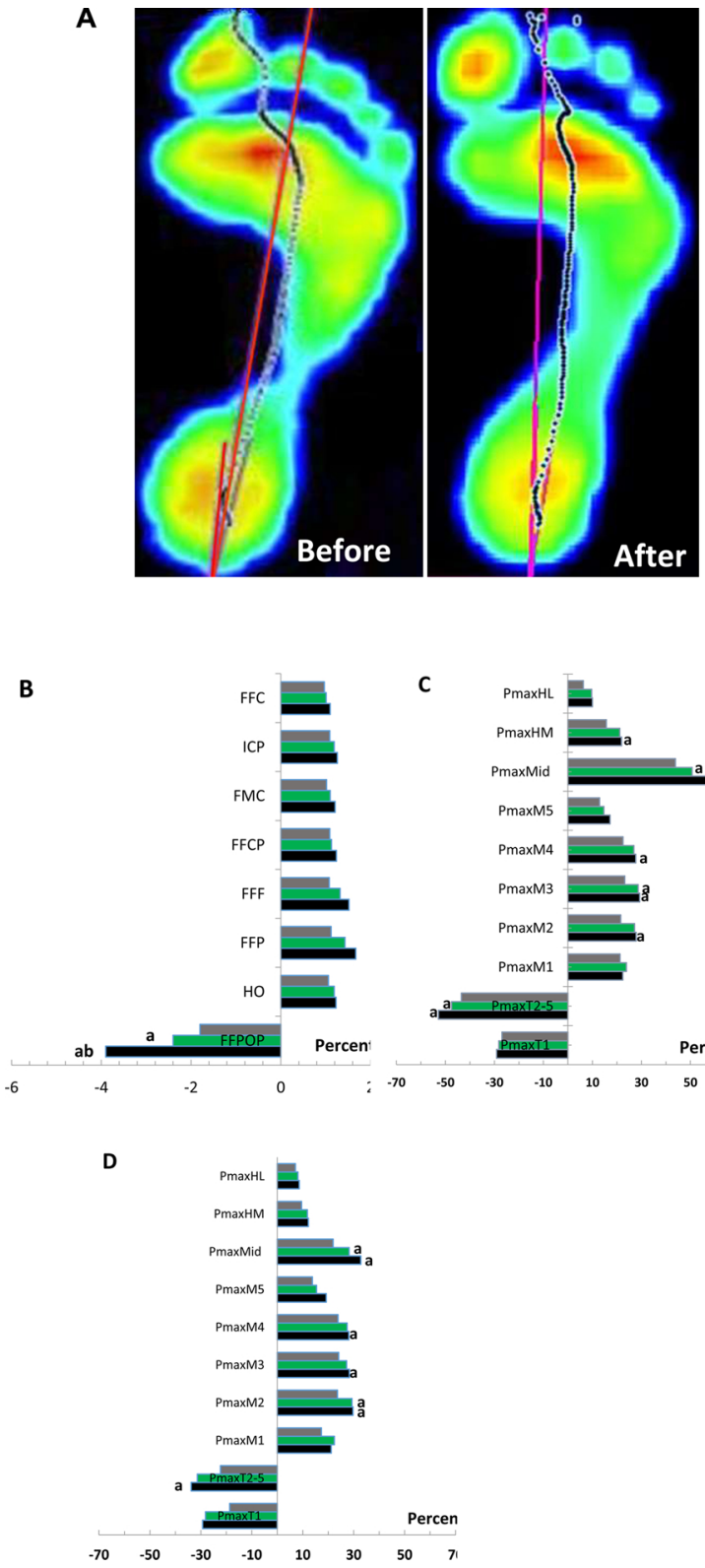

Fig. 1. Difference in A) peak plantar pressure distribution during running before and after $30 \mathrm{~min}$ running, B) medio-lateral pressure distribution underneath the forefoot at four instants (FMC, FFF, HO, and LFC) and during four phases of foot roll-over (ICP, FFCP, FFP, and FFPOP) (note: a positive ratio indicates a medially directed pressure distribution, a negative ratio a laterally directed pressure distribution C) peak plantar pressure, D) absolute impulse for the ten anatomical foot zones and between groups ( $\square$, and $\square$ ).

Abbreviations: FFC; first foot contact, FMC; first metatarsal contact, FFF; forefoot flat, HO; heel off, LFC; last foot contact, ICP; initial contact phase, FFCP; forefoot contact phase, FFP; foot flat phase, FFPOP; forefoot push off phase. Note. ${ }^{\text {a }}$; indicate significant difference from normal group, ${ }^{\text {b; }}$ indicates differences from overweight group.

but body mass, BMI, BFP, and WHR were all higher in obese than overweight people and the lowest in normal-weight people ( $\mathrm{p}<0.05)$. TCT was highest in obese and lowest in normal-weight people, with that of overweight people in between. The TCT was increased after running in all groups (Table 1 ).

The distribution of pressures was shifted from the toes to the forefoot and MF after running (Fig. 1A). The pressure distribution was medially directed at the four instants of running (FMC, FFF, HO, and LFC) and during the three phases of foot roll-over (ICP, FFCP, and FFP), irrespective of group. During FFPOP, the medial to lateral pressure displacement was more for obese and overweight than for normalweight people (Fig. 1B). The peak pressure was higher after running in all foot zones ( $\mathrm{p}<0.05$ ), except the T1, M5 and lateral heal (Fig. 1A, C).

Group effects and group $\times$ time interactions were found across the following variables: peak pressures $\mathrm{M}_{2}\left(\mathrm{~F}_{(1,57)}=8.8 ; \mathrm{p}=0.01\right.$; $\eta 2 \mathrm{p}=0.21$ and $\mathrm{F}_{(2,57)}=10.6 ; \mathrm{p}=0.01 ; \eta 2 \mathrm{p}=0.24$; respectively), $\mathrm{M}_{3}\left(\mathrm{~F}_{(1,57)}=6.9 ; \mathrm{p}=0.02 ; \eta 2 \mathrm{p}=0.18\right.$ and $\mathrm{F}_{(2,57)}=9.7 ; \mathrm{p}=0.01$; $\eta 2 \mathrm{p}=0.23$; respectively), $\mathrm{M}_{4}\left(\mathrm{~F}_{(1,57)}=4.8 ; \mathrm{p}=0.04 ; \eta 2 \mathrm{p}=0.12\right.$ and $\mathrm{F}_{(2,57)}=12.8 ; \mathrm{p}=0.001 ; \eta 2 \mathrm{p}=0.26$; respectively), $\mathrm{MF}\left(\mathrm{F}_{(1,57)}\right.$ $=12.4 ; \mathrm{p}=0.001 ; \eta 2 \mathrm{p}=0.26$ and $\mathrm{F}_{(2,57)}=18.9 ; \mathrm{p}=0.001$; $\eta 2 \mathrm{p}=0.34 ;$ respectively $)$ HM $\left(\mathrm{F}_{(1,57)}=7.8 ; \mathrm{p}=0.01 ; \eta 2 \mathrm{p}=0.20\right.$ and $\mathrm{F}_{(2,57)}=11.6 ; \mathrm{p}=0.001 ; \eta 2 \mathrm{p}=0.25$; respectively) and toe $2.5(\mathrm{~F}$ $(1,57)=9.5 ; \mathrm{p}=0.01 ; \eta 2 \mathrm{p}=0.23$ and $\mathrm{F}_{(2,57)}=11.8 ; \mathrm{p}=0.001$; $\eta 2 p=0.25$; respectively). Fig. 1C illustrates the results of the post-hoc tests that showed that peak plantar-pressure underneath M2, 3 and 4, MF and HM were higher in obese than normal-weight people. In addition, peak plantar-pressure underneath $\mathrm{M} 3$ and MF were higher in overweight than normal-weight people. Peak plantar-pressure underneath the MF was also higher in obese than overweight people. Only peak plantar-pressure underneath toe $2-5$ was lower in overweight and obese than normal-weight people $(\mathrm{p}<0.05)$.

A significant time effect was found for absolute impulse of all foot zones ( $\mathrm{p}<0.05)$, except $\mathrm{T} 1$ and lateral heal peak pressure. A significant group and group $\times$ time interaction were found across the following variables: absolute impulse $\mathrm{M}_{1}(16.4 ; \mathrm{p}=0.001 ; \eta 2 \mathrm{p}=0.31$ and $\mathrm{F}_{(2,57)}=21.3 ; \mathrm{p}=0.001 ; \eta 2 \mathrm{p}=0.38$; respectively $), \mathrm{M}_{2}\left(\mathrm{~F}_{(1,57)}\right.$ $=28.8 ; \mathrm{p}=0.001 ; \eta 2 \mathrm{p}=0.44$ and $\mathrm{F}_{(2,57)}=37.8 ; \mathrm{p}=0.001$; $\eta 2 \mathrm{p}=0.51 ;$ respectively $), \mathrm{M}_{3}\left(\mathrm{~F}_{(1,57)}=23.8 ; \mathrm{p}=0.001 ; \eta 2 \mathrm{p}=0.40\right.$ and $\mathrm{F}_{(2,57)}=18.7 ; \mathrm{p}=0.001 ; \eta 2 \mathrm{p}=0.34$; respectively), $\mathrm{M}_{4}\left(\mathrm{~F}_{(1,57)}\right.$ $=12.4 ; \mathrm{p}=0.001 ; \eta 2 \mathrm{p}=0.26$ and $\mathrm{F}_{(2,57)}=18.9 ; \mathrm{p}=0.001$; $\eta 2 \mathrm{p}=0.34 ;$ respectively), $\mathrm{MF}\left(\mathrm{F}_{(1,57)}=4.8 ; \mathrm{p}=0.04 ; \eta 2 \mathrm{p}=0.12\right.$ and $\mathrm{F}_{(2,57)}=12.8 ; \mathrm{p}=0.001 ; \eta 2 \mathrm{p}=0.26$; respectively), $\operatorname{HM}\left(\mathrm{F}_{(1,57)}\right.$ $=4.8 ; \mathrm{p}=0.04 ; \eta 2 \mathrm{p}=0.12$ and $\mathrm{F} \quad(2,57)=12.8 ; \mathrm{p}=0.001$; $\eta 2 \mathrm{p}=0.26 ;$ respectively $)$ and toe t. $_{2.5}\left(\mathrm{~F}_{(1,57)}=4.8 ; \mathrm{p}=0.04\right.$; $\eta 2 \mathrm{p}=0.12$ and $\mathrm{F}_{(2,57)}=12.8 ; \mathrm{p}=0.001 ; \eta 2 \mathrm{p}=0.26$; respectively). Post-hoc tests showed that the impulse underneath M2, 3 and 4, MF and HM were higher in obese than normal-weight people. In addition, the impulse underneath M2 and MF were higher in overweight than normal-weight people. Only the impulse underneath toe $2-5$ were lower in obese than normal-weight people ( $p<0.05$ ) (Fig. 1D).

Table 2 shows the outcome of the stepwise multiple linear regressions to determine the contribution of predictor variables (BMI, BFP, WHR, plantarflexor muscle strength, pantarflexor muscle endurance, dorsiflexor muscle strength, dorsiflexor muscle endurance, invertor muscle strength, invertor muscle endurance, evertor muscle strength and evertor muscle endurance) to the dynamic peak plantar-pressure distribution before running. It can be seen, that only BMI was a significant predictor of TCT (20\%), peak plantar-pressures underneath the $\mathrm{M}_{1}(18 \%)$ and $\mathrm{M}_{4}(19 \%)$, and impulses in $\mathrm{M}_{1}(21 \%), \mathrm{M}_{2}(39 \%)$ and $\mathrm{M}_{5}$ (36\%). BMI was also the main predictor of variation of DAI (52\%) and impulse in the $\mathrm{T}_{1}(28 \%)$. Plantarflexor and invertor muscles strength were only minor predictors for the dynamic plantar-pressure distribution. In addition, BFP explained the largest proportion of the variation in the peak plantar-pressure underneath the $\mathrm{M}_{1}(29 \%)$ and midfoot (38\%) and impulse in the midfoot (49\%), with minimal contributions of plantarflexor and invertor muscles strength (Table 2).

After running, the contributions of plantarflexor and invertor muscles strength, and endurance became more prominent than before running. However, BMI was still the only predictor of variation of the TCT (9\%) and peak plantar-pressures underneath the $M_{4}(31 \%)$ and $M_{5}$ $(18 \%)$. In addition, BFP explained the largest proportion of the variation of the peak plantar-pressure underneath the $\mathrm{M}_{1}(38 \%)$ and of the impulse in the $M_{5}(17 \%)$, and WHR was a predictor for the impulse in the $\mathrm{M}_{5}$ (47\%) with minimal contributions of invertor muscles strength. 
Table 2

Summary of Stepwise Multiple Linear Regression Analysis for Predictors of Plantar Pressure Distribution before Running.

\begin{tabular}{|c|c|c|c|c|c|c|c|c|c|c|}
\hline \multirow[t]{2}{*}{ Dependent variables } & \multirow[t]{2}{*}{ Model } & \multirow[t]{2}{*}{ Predictor variables } & \multirow[t]{2}{*}{ Adjusted $\mathrm{R}^{2}$} & \multirow[t]{2}{*}{$\mathrm{F}$} & \multirow[t]{2}{*}{$\mathrm{p}$} & \multirow[t]{2}{*}{ B } & \multirow[t]{2}{*}{$\mathrm{t}$} & \multirow[t]{2}{*}{$\mathrm{p}$} & \multicolumn{2}{|c|}{$95.0 \%$ Confidence Interval for B } \\
\hline & & & & & & & & & Lower band & Upper band \\
\hline TCT (ms) & Model 1 & BMI & 0.20 & 15.7 & 0.001 & 3.3 & 3.9 & 0.001 & 1.6 & 5.0 \\
\hline \multirow[t]{3}{*}{ DAI (\%) } & Model 3 & BMI & 0.52 & 22.1 & 0.001 & 0.15 & 3.2 & 0.001 & 0.05 & 0.2 \\
\hline & & IMS (BWR) & & & & -0.12 & -2.8 & 0.007 & -0.2 & -0.04 \\
\hline & & PFMS (BWR) & & & & -0.02 & -2.6 & 0.01 & -0.04 & -0.005 \\
\hline \multirow[t]{2}{*}{$\operatorname{PmaxT}_{1}\left(\mathrm{~N} / \mathrm{cm}^{2}\right)$} & Model 2 & PFMS (BWR) & 0.14 & 5.9 & 0.001 & 0.54 & 3.1 & 0.003 & 0.14 & 0.95 \\
\hline & & BMI & & & & 0.39 & 2.6 & 0.01 & 0.05 & 0.63 \\
\hline \multirow[t]{2}{*}{$\operatorname{PmaxT}_{2-5}\left(\mathrm{~N} / \mathrm{cm}^{2}\right)$} & Model 2 & PFMS (BWR) & 0.38 & 19.3 & 0.001 & 0.78 & 3.8 & 0.001 & 0.37 & 1.2 \\
\hline & & BMI & & & & 0.20 & 2.9 & 0.01 & 0.06 & 0.33 \\
\hline $\operatorname{PmaxM}_{1}\left(\mathrm{~N} / \mathrm{cm}^{2}\right)$ & Model 1 & BMI & 0.18 & 13.8 & 0.001 & 1.5 & 3.7 & 0.001 & 0.72 & 2.4 \\
\hline $\mathrm{PmaxM}_{4}\left(\mathrm{~N} / \mathrm{cm}^{2}\right)$ & Model 1 & BMI & 0.19 & 14.2 & 0.001 & 1.1 & 3.8 & 0.001 & 0.52 & 1.7 \\
\hline $\operatorname{PmaxM}_{5}\left(\mathrm{~N} / \mathrm{cm}^{2}\right)$ & Model 1 & BFP & 0.29 & 25.4 & 0.001 & 0.72 & 5.0 & 0.001 & 0.43 & 1.0 \\
\hline \multirow[t]{2}{*}{ PmaxMid foot $\left(\mathrm{N} / \mathrm{cm}^{2}\right)$} & Model 2 & $\mathrm{BFP}$ & 0.38 & 19.2 & 0.001 & 0.55 & 3.5 & 0.001 & 0.24 & 0.86 \\
\hline & & IMS (BWR) & & & & -0.6 & -3.2 & 0.002 & -0.97 & -0.23 \\
\hline \multirow[t]{2}{*}{$\operatorname{Impuls}_{1}\left(\mathrm{~N} / \mathrm{cm}^{2}\right)$} & Model 2 & BMI & 0.28 & 12.5 & 0.001 & 0.12 & 4.6 & 0.001 & 0.07 & 0.2 \\
\hline & & PFMS (BWR) & & & & 0.02 & 3.7 & 0.001 & 0.01 & 0.03 \\
\hline \multirow[t]{2}{*}{$\operatorname{ImpulsT}_{2-5}\left(\mathrm{~N} / \mathrm{cm}^{2}\right)$} & Model 2 & PFMS (BWR) & 0.31 & 14.3 & 0.001 & 0.01 & 4.9 & 0.001 & 0.005 & 0.01 \\
\hline & & BMI & & & & 0.04 & 4.0 & 0.001 & 0.02 & 0.06 \\
\hline $\operatorname{ImpulsM}_{1}\left(\mathrm{Ns} / \mathrm{cm}^{2}\right)$ & Model 1 & BMI & 0.21 & 16.6 & 0.001 & 0.13 & 4.1 & 0.001 & 0.07 & 0.19 \\
\hline $\operatorname{ImpulsM}_{2}\left(\mathrm{Ns} / \mathrm{cm}^{2}\right)$ & Model 1 & BMI & 0.39 & 39 & 0.001 & 0.14 & 6.3 & 0.001 & 0.1 & 0.18 \\
\hline ImpulsM ${ }_{5}\left(\mathrm{Ns} / \mathrm{cm}^{2}\right)$ & Model 1 & BMI & 0.36 & 34.3 & 0.001 & 0.06 & 5.8 & 0.001 & 0.04 & 0.08 \\
\hline \multirow[t]{2}{*}{ ImpulsMid foot(Ns $\left./ \mathrm{cm}^{2}\right)$} & Model 3 & $\mathrm{BFP}$ & 0.48 & 28.9 & 0.001 & 0.05 & 4.5 & 0.001 & 0.03 & 0.07 \\
\hline & & PFMS (BWR) & & & & -0.008 & 3.4 & 0.001 & -0.01 & -0.003 \\
\hline
\end{tabular}


WHR; Waist-hip ratio, PFMS; Plantarflexor Muscle Strength, PFME; Plantarflexor Muscle Endurance, IMS; Invertor Muscle Strength.

Note: B; coefficient for predictor variable, significance defined as $\mathrm{p} \leq 0.05$.

For variation of DAI (38\%) and the peak plantar-pressures underneath the $\mathrm{T}_{1}(46 \%)$ and $\mathrm{T}_{2-5}(37 \%)$ the only predictors were foot muscle characteristics as plantarflexor and invertor muscles endurance and strength. Plantarflexor and invertor muscle endurance and strength also explained the largest proportion of the variation for the peak plantarpressures underneath the $\mathrm{M}_{2}(30 \%)$ and midfoot (57\%), and impulse in the $\mathrm{T}_{1}(36 \%), \mathrm{T}_{2-5}(37 \%), \mathrm{M}_{1}(58 \%)$ and $\mathrm{M}_{3}$ (39\%), with some contribution of BMI, BFP, and WHR. BMI was also the main predictor of variation of DAI $(52 \%)$ and impulse in the $\mathrm{T}_{1}(28 \%)$, with some contribution of plantarflexor endurance, and invertor muscles strength (Table 3).

\section{Discussion}

The main outcome of the present study is that BMI is the more important predictor of plantar pressure and impulse both before and after 30 min running. Before running, it explains from $14 \%$ (for T1) to $38 \%$ (for T2-5) of peak plantar-pressure and between $21 \%$ (for M1) to $48 \%$ (for midfoot) of the impulse underneath different foot zones either independently or in combination with other variables. The importance of muscle strength and endurance for plantar pressure and impulse became more prominent after prolonged running: they predicted from $30 \%$ (for M2) to $57 \%$ (for MF) of peak plantar-pressure and from $36 \%$ (for T1) to 58\% (for M1) impulse change underneath different foot zones, with weaker, or less fatigue resistant, muscles being associated with higher plantar pressures and impulses.

Similar to previous observations for long-distance race runners [1], it was found that after $30 \mathrm{~min}$ of running, TCT was increased. This increase was larger in obese than normal-weight runners, something also seen in normal-weight and obese children [23]. It has been suggested that such an increase in TCT is caused by a slower stretch-shortening cycle as a consequence of muscle fatigue [17]. TCT was increased less in long-distance runners than in the recreational runners in our study, although their run distance was greater. It thus seems that the TCT was more affected by foot muscle endurance and strength, and the participant BMI and mass than the running distance. In other words, the higher the body mass and BMI of the participant and the lower the endurance and strength of muscles of the foot, the larger the increase in TCT during a run. The larger load on the muscles of obese people may result in an earlier onset of muscle fatigue and underlie the higher TCT in obese than normal-weight runners. The increasing TCT may enable participants to maintain a constant horizontal impulse in the face of a decreased neuromuscular capacity due to fatigue [19] and provide better stability at the expense of a decreased propulsion phase duration [34].

In the present study, the peak pressure underneath the toes (T1 and T2-5) was reduced after 30 min of running and shifted to the forefoot. It appeared that lower plantarflexor muscle endurance correlated with a higher forefoot peak pressure. The results of our study are in line with the results of a cadaver model of the terminal stance simulator, which indicated that a low extrinsic toe flexor strength is associated with an increased load under the forefoot region [35]. The explanation for the lower pressure underneath the toes after running in previous studies was foot and ankle muscle fatigue, especially fatigue of the plantarflexor muscles that would result in reduced use of the toes during the push-off period $[7,8]$. In line with this, the intrinsic and extrinsic flexor muscle fatigue can increase the dorsiflexion moments in the metatarsophalangeal joints and ultimately cause heavy loading in the forefoot area. It should also be considered that the larger body mass of obese than non-obese people will inevitably lead to greater subtalar joint pronation moments that will, if muscle mass is not adapted, cause an earlier onset of muscle fatigue. As a consequence of the earlier onset of muscle fatigue the magnitude of abnormal subtalar joint pronation will increase, which in turn will lead to an enhanced unlocking of the oblique axis of the mid-tarsal joint in terminal stance. The result is then an unstable first ray in propulsion as the ground reaction force pushes up the first ray and decreases loading on the first metatarsal head and transfers the loading to the second and third metatarsal heads, as in fact seen in our participants. This excessive loading of the second and third metatarsal heads may contribute to the increased risk of pathologies in these areas in runners [36]. However, the plantar pressure seems to return to baseline after a $24-\mathrm{h}$ rest, probably due to muscle recovery [37].

In our study, BMI and BFP were the primary predictors of pressure 
Table 3

Summary of Stepwise Multiple Linear Regression Analysis for Predictors of Plantar Pressure Changes after Running.

\begin{tabular}{|c|c|c|c|c|c|c|c|c|c|c|}
\hline \multirow[t]{2}{*}{ Dependent variables } & \multirow[t]{2}{*}{ Model } & \multirow[t]{2}{*}{ Predictor variables } & \multirow[t]{2}{*}{ Adjacent $\mathrm{R}^{2}$} & \multirow[t]{2}{*}{$\mathrm{F}$} & \multirow[t]{2}{*}{$\mathrm{p}$} & \multirow[t]{2}{*}{ B } & \multirow[t]{2}{*}{$\mathrm{t}$} & \multirow[t]{2}{*}{$\mathrm{P}$} & \multicolumn{2}{|c|}{$95.0 \%$ Confidence Interval for B } \\
\hline & & & & & & & & & Lower band & Upper band \\
\hline TCT (ms) & Model 2 & BMI & 0.09 & 6.5 & 0.01 & 0.42 & 2.5 & 0.01 & 0.09 & 0.75 \\
\hline \multirow[t]{2}{*}{ DAI (\%) } & Model 2 & IMS(BWR) & 0.38 & 19.5 & 0.001 & -0.13 & -3.8 & 0.001 & -0.2 & -0.06 \\
\hline & & PFME & & & & 0.02 & -3.2 & 0.001 & -0.04 & -0.01 \\
\hline \multirow[t]{2}{*}{$P \max T_{1}\left(\mathrm{~N} / \mathrm{cm}^{2}\right)$} & Model 2 & PFME & 0.46 & 26.6 & 0.001 & -0.1 & -4.9 & 0.001 & -0.15 & -0.06 \\
\hline & & IMS (BWR) & & & & -0.14 & -2.3 & 0.03 & -0.26 & -0.02 \\
\hline \multirow[t]{2}{*}{$\operatorname{PmaxT}_{2-5}\left(\mathrm{~N} / \mathrm{cm}^{2}\right)$} & Model 2 & PFME & 0.37 & 18.9 & 0.001 & -0.08 & -3.8 & 0.001 & -0.12 & -0.04 \\
\hline & & IME & & & & -0.09 & -2.7 & 0.03 & -0.16 & -0.02 \\
\hline \multirow[t]{2}{*}{$\operatorname{PmaxM}_{1}\left(\mathrm{~N} / \mathrm{cm}^{2}\right)$} & Model 2 & BFP & 0.38 & 18.1 & 0.001 & 0.7 & 4.7 & 0.001 & 0.3 & 0.8 \\
\hline & & IMS(BWR) & & & & -0.4 & -3.6 & 0.001 & -0.6 & -0.2 \\
\hline \multirow[t]{2}{*}{$\mathrm{PmaxM}_{2}\left(\mathrm{~N} / \mathrm{cm}^{2}\right)$} & Model 3 & PFME & 0.30 & 13.3 & 0.001 & -0.13 & -2.9 & 0.001 & -0.2 & -0.04 \\
\hline & & BMI & & & & 0.39 & 3.3 & 0.006 & 012 & 0.67 \\
\hline \multirow[t]{2}{*}{$\operatorname{PmaxM}_{3}\left(\mathrm{~N} / \mathrm{cm}^{2}\right)$} & Model 2 & BMI & 0.42 & 22.2 & 0.001 & 0.48 & 6.0 & 0.001 & 0.32 & 0.64 \\
\hline & & PFMS(BWR) & & & & -0.14 & -3.7 & 0.001 & -0.21 & -0.06 \\
\hline $\mathrm{PmaxM}_{4}\left(\mathrm{~N} / \mathrm{cm}^{2}\right)$ & Model 1 & BMI & 0.31 & 26.8 & 0.001 & 0.46 & 5.2 & 0.001 & 0.28 & 0.65 \\
\hline $\operatorname{PmaxM}_{5}\left(\mathrm{~N} / \mathrm{cm}^{2}\right)$ & Model 1 & BMI & 0.18 & 13.5 & 0.001 & 0.33 & 3.7 & 0.001 & 0.15 & 0.51 \\
\hline \multirow[t]{3}{*}{ PmaxMid foot $\left(\mathrm{N} / \mathrm{cm}^{2}\right)$} & Model 3 & IME (BWR) & 0.57 & 26.8 & 0.001 & -0.18 & -3.7 & 0.001 & -0.27 & -0.08 \\
\hline & & BFP & & & & 0.27 & 2.9 & 0.006 & 0.08 & 0.5 \\
\hline & & PFME & & & & -0.05 & -2.7 & 0.009 & -0.08 & -0.01 \\
\hline \multirow[t]{2}{*}{$\operatorname{PmaxMH}\left(\mathrm{N} / \mathrm{cm}^{2}\right)$} & Model 1 & BMI & 0.42 & 22.2 & 0.001 & 0.3 & 4.7 & & 0.17 & 0.43 \\
\hline & & IMS (BWR) & & & & -0.14 & -2.3 & 0.03 & -0.26 & -0.02 \\
\hline \multirow[t]{2}{*}{$\operatorname{Impuls}_{1}\left(\mathrm{~N} / \mathrm{cm}^{2}\right)$} & Model 2 & PFME & 0.36 & 17.6 & 0.001 & -0.01 & -4.4 & 0.001 & -0.01 & -0.005 \\
\hline & & BFP & & & & 0.02 & 2.1 & 0.04 & 0.001 & 0.03 \\
\hline \multirow[t]{2}{*}{$\operatorname{ImpulsT}_{2-5}\left(\mathrm{~N} / \mathrm{cm}^{2}\right)$} & Model 2 & PFME & 0.37 & 17.9 & 0.001 & -0.006 & -3.4 & 0.001 & -0.009 & -0.002 \\
\hline & & BMI & & & & 0.02 & 2.5 & 0.02 & 0.004 & 0.04 \\
\hline \multirow[t]{2}{*}{$\operatorname{ImpulsM}_{1}\left(\mathrm{Ns} / \mathrm{cm}^{2}\right)$} & Model 2 & PFMS(BWR) & 0.58 & 41.7 & & -0.03 & -7.3 & 0.001 & -0.03 & -0.02 \\
\hline & & BMI & & & & 0.02 & 2.1 & 0.04 & 0.001 & 0.04 \\
\hline \multirow[t]{2}{*}{$\mathrm{ImpulsM}_{2}\left(\mathrm{Ns} / \mathrm{cm}^{2}\right)$} & Model 2 & WHR & 0.47 & 26.9 & 0.001 & 0.03 & 5.4 & 0.001 & 0.02 & 0.04 \\
\hline & & IMS(BWR) & & & & -0.02 & -2.3 & 0.02 & -0.04 & -0.003 \\
\hline \multirow[t]{2}{*}{$\operatorname{ImpulsM}_{3}\left(\mathrm{Ns} / \mathrm{cm}^{2}\right)$} & Model 2 & PFME & 0.39 & 19.9 & 0.001 & -0.007 & -3.9 & 0.001 & -0.01 & -0.003 \\
\hline & & WHR & & & & 0.015 & 2.7 & 0.01 & 0.004 & 0.03 \\
\hline $\operatorname{ImpulsM}_{5}\left(\mathrm{Ns} / \mathrm{cm}^{2}\right)$ & Model 1 & BFP & 0.17 & 12.7 & 0.001 & 0.03 & 3.6 & 0.001 & 0.01 & 0.05 \\
\hline \multirow[t]{3}{*}{ ImpulsMid foot(Ns/ $\left.\mathrm{cm}^{2}\right)$} & Model 3 & PFME & 0.54 & 23.9 & 0.001 & -0.02 & -1.9 & 0.05 & -0.05 & 0.01 \\
\hline & & BFP & & & & 0.03 & 3.5 & 0.001 & 0.01 & 0.04 \\
\hline & & IMS(BWR) & & & & -0.02 & -2.5 & 0.02 & -0.04 & -0.004 \\
\hline \multirow[t]{2}{*}{$\mathrm{ImpulsH}_{\mathrm{M}}\left(\mathrm{Ns} / \mathrm{cm}^{2}\right)$} & Model 1 & BMI & 0.49 & 29.2 & 0.001 & 0.04 & 5.7 & 0.001 & 0.02 & 0.05 \\
\hline & & IMS(BWR) & & & & -0.01 & -2.1 & 0.04 & -0.03 & -0.001 \\
\hline
\end{tabular}


Index, WHR; Waist-hip ratio, PFMS; Plantarflexor Muscle Strength, PFME; Plantarflexor Muscle Endurance, IMS; Invertor Muscle Strength.

Note: B; coefficient for predictor variable, significance defined as $\mathrm{p} \leq 0.05$.

and impulse in the foot (except for heel), with some contribution of muscle (specifically plantarflexor and invertor muscles) strength and endurance, particularly after $30 \mathrm{~min}$ of running. Butterworth, Urquhart, Landorf, Wluka, Cicuttini and Menz [24] found that body mass is positively related to loading of the foot, particularly the fore- and MF. This suggests that weight reduction may be a more effective initial strategy than mechanical interventions (such as foot orthoses) for reducing plantar loading and prevention of foot pain that is common in obese people [3,9]. This suggestion is supported by a previous study that showed that even a modest weight reduction yielded significant reductions in plantar loading, without significant and clinically meaningful changes in foot structure and gait parameters [25]. In addition, weight loss is associated with an increase in the strength of the foot muscles relative to body mass [26], which will delay muscle fatigue and thus help further normalizing plantar-pressure and impulse. This is important as we found that a low relative plantarflexor and invertor muscle strength and endurance were associated with high pressure and impulse in MF and M2, respectively. This suggests that in addition to weight loss, also strengthening of these muscles may, through improving dynamic foot posture, help to normalize plantar-pressure and impulse in these areas.

The medial arch of the foot is a deformable structure and during midstance its height can decrease by about $10 \mathrm{~mm}$ and its length can increase by about $4 \mathrm{~mm}$ [38]. The medial arch plays an important role in the transfer of ground reaction forces through the foot to the rest of the body $[28,38]$. The passive elasticity of the ligaments and the active contractility of muscles are important to maintain the foot arch [39]. Therefore, strengthening the intrinsic and extrinsic foot muscles that control foot pronation may well prevent or attenuate excessive pronation $[6,40]$ that in turn may help prevent overuse injuries related to excessive pronation [41]. For instance, the tibialis anterior plays a role in rising the summit of the medial longitudinal arch, while the tibialis posterior and peroneus longus provide sling support for the medial longitudinal arch, and the muscles act as longitudinal bowstrings [42]. As plantarflexor and invertor muscles strength were predictors for dynamic foot posture and plantar-pressure in the MF, fatigue of the plantarflexor muscles would increase foot pronation, which is indeed what we observed. [18] also reports that after running there is a shift of loading from the lateral to the medial area of the heel related to pronation. In line with our findings, Weist, Eils and Rosenbaum [8] reported that participants with lower relative strength of plantarflexors and invertors have an even more pronounced increase in foot pronation after $30 \mathrm{~min}$ of running. The augmented compliance of the medial arch under fatigue conditions may increase the workload of plantarflexor and invertor muscles that are already fatigued even further, leading thus via a positive feedback loop to further local fatigue. Improving the muscle strength and endurance of all antipronator muscles, especially the tibialis posterior muscle, should thus be a priority in preventing injuries related to pronation. The other tasks of the muscles during the running activities is to absorb energy during the stance phase to minimize the impact forces on the bony tissue [8]. Therefore, the fatigue-related decrease in foot muscle strength during 30 min running 
may result in increased loading underneath the foot and especially MF. This mechanism might help to explain the increased incidence of foot and lower leg stress fractures and medial tibial stress syndrome under fatigued conditions specifically in obese people $[9,21]$.

There are several limitations in yhe present study. Twenty to forty year-old men were only included, which limits generalizability of the results to women and children or older adults. In addition, a range of potential predictors, such as radiographic measures, plantar fat pad thickness and ankle joint range of motion (dorsiflexion and plantarflexion) were not measured in our study. In the present study, the strike pattern during running was not controlled and changes in strike pattern that contributes to the observed changes in the plantar pressure pattern may have been missed. While there was no direct measure of foot pronation or supination using a motion capture system in our study, and static foot posture does not predict dynamic foot function [13], the DAI was calculated [28], which is a good indicator of the dynamic nature of the foot during gait [14]. Previous studies have demonstrated that at least 3 to 5 trials are required to collect consistent plantar pressure data when walking [43]. Although it would have been desirable to collect data from more than 3 trials as there is a larger heterogeneity between trials when running, other studies have also collected data from 3 trials only during running [9,17,20,37].

\section{Conclusion}

The results of this study suggest that obesity is associated with high dynamic peak foot pressures and impulse underneath different foot zones both before and after $30 \mathrm{~min}$ running and that this high foot pressure is primarily due to a high BMI and BFP. In addition, after prolonged running the importance of foot muscle strength and endurance became more prominent and foot muscle fatigue aggravated peak foot pressures in obese runners. Therefore, clinicians dealing with obese people should consider the detrimental effect of obesity on plantar loading to prevent foot pain and injuries related to high plantar pressures, particularly at the beginning of the weight control process. It is recommended to health care professionals to emphasize non-weight bearing exercises (such as swimming or cycling) more than weightbearing exercise at least in this stage. Over-weight or obese runners may be advised to utilize shoes with increased forefoot cushioning in addition to muscle strength/endurance training. Running shoes should be able to control overpronation, especially in fatigue conditions when foot stabilizing muscles lose their control over the rollover process, particularly in obese people. To prevent, or at least reduce, the lower leg and foot injuries in obese people especially in the fatigue conditions, foot orthoses can also be used to support the medial arch of the foot to reduce plantar-pressure during mid-stance of running.

\section{Conflict of interest}

The authors declare that there is no financial/personal interest or belief that could affect their objectivity.

\section{Funding}

This research did not receive any specific grant from funding agencies in the public, commercial, or not-for-profit sectors.

\section{References}

[1] Williams EP, Mesidor M, Winters K, et al. Overweight and obesity: prevalence, consequences, and causes of a growing public health problem. Current Obesity Rep 2015;4(3):363-70. https://doi.org/10.1007/s13679-015-0169-4.

[2] World Health Organization. Obesity and Overweight factsheet from the WHO. 2018. (February 16). Retrieved from. https://www.who.int/news-room/fact-sheets/ detail/obesity-and-overweight.

[3] Paulis W, Silva S, Koes B, et al. Overweight and obesity are associated with musculoskeletal complaints as early as childhood: a systematic review. Obesity Rev
2014;15(1):52-67. https://doi.org/10.1111/obr.12067.

[4] Taunton JE, Ryan MB, Clement DB, et al. A prospective study of running injuries: the Vancouver Sun Run "In Training" clinics. Br J Sports Med 2003;37(3):239-44. https://doi.org/10.1136/bjsm.37.3.239.

[5] Buist I, Bredeweg SW, Bessem B, et al. Incidence and risk factors of running-related injuries during preparation for a 4-mile recreational running event. Br J Sports Med 2010;44(8):598-604. https://doi.org/10.1136/bjsm.2007.044677.

[6] Fiolkowski P, Brunt D, Bishop M, et al. Intrinsic pedal musculature support of the medial longitudinal arch: an electromyography study. J foot Ankle Surg 2003;42(6):327-33. https://doi.org/10.1053/j.jfas.2003.10.003.

[7] Christina KA, White SC, Gilchrist LA. Effect of localized muscle fatigue on vertical ground reaction forces and ankle joint motion during running. Human Mov Sci 2001;20(3):257-76. https://doi.org/10.1016/S0167-9457(01)00048-3.

[8] Weist R, Eils E, Rosenbaum D. The influence of muscle fatigue on electromyogram and plantar pressure patterns as an explanation for the incidence of metatarsal stress fractures. Am J Sports Med 2004;32(8):1-6. https://doi.org/10.1177/ 0363546504265191.

[9] Walsh TP, Butterworth PA, Urquhart DM, et al. Increase in body weight over a twoyear period is associated with an increase in midfoot pressure and foot pain. $J$ Foot Ankle Res 2017;10(1):31. https://doi.org/10.1186/s13047-017-0214-5.

[10] Brund RB, Rasmussen S, Nielsen RO, et al. Medial shoe-ground pressure and specific running injuries: a 1-year prospective cohort study. J Sci Med Sport 2017;20(9):830-4. https://doi.org/10.1016/j.jsams.2017.04.001.

[11] Horwood AM, Chockalingam N. Defining excessive, over, or hyper-pronation: a quandary. Foot 2017;31(49). https://doi.org/10.1016/j.foot.2017.03.001.

[12] Müller S, Carlsohn A, Müller J, et al. Static and dynamic foot characteristics in children aged 1-13 years: a cross-sectional study. Gait Posture 2012;35(3):389-94. https://doi.org/10.1016/j.gaitpost.2011.10.357.

[13] Paterson KL, Clark RA, Mullins A, et al. Predicting dynamic foot function from static foot posture: comparison between visual assessment, motion analysis, and a commercially available depth camera. J Orthop Sports Phys Ther 2015;45(10):789-98. https://doi.org/10.2519/jospt.2015.5616.

[14] Faria A, Gabriel R, Abrantes J, et al. The relationship of body mass index, age and triceps-surae musculotendinous stiffness with the foot arch structure of postmenopausal women. Clin Biomech 2010;25(6):588-93. https://doi.org/10.1016/j clinbiomech.2010.02.014.

[15] Imaizumi K, Iwakami Y, Yamashita K. Analysis of foot pressure distribution data for the evaluation of foot arch type. 2011 annual internationalc of the IEEE engineering in medicine and biology society. IEEE 2011:7388-92.

[16] Wong CK, Weil R, de Boer E. Standardizing foot-type classification using arch index values. Physiother Canada 2012;64(3):280-3. https://doi.org/10.3138/ptc. 2011-40.

[17] Debenham JR, Travers M, Gibson W, et al. Eccentric fatigue modulates stretchshortening cycle effectiveness-a possible role in lower limb overuse injuries. Int $\mathrm{J}$ Sports Med 2015;10(11):21-35. https://doi.org/10.1055/s-0035-1549923.

[18] Escamilla-Martínez E, Martínez-Nova A, Gómez-Martín B, et al. The effect of moderate running on foot posture index and plantar pressure distribution in male recreational runners. J Am Podiatric Med Assoc 2013;103(2):121-5. https://doi. org $/ 10.7547 / 1030121$.

[19] Fourchet F, Kelly L, Horobeanu C, et al. High-intensity running and plantar-flexor fatigability and plantar-pressure distribution in adolescent runners. J Athletic training 2015;50(2):117-25. https://doi.org/10.4085/1062-6050-49.3.90.

[20] Wan JJ, Qin Z, Wang PY, et al. Muscle fatigue: general understanding and treatment. Exp Mol Med 2017;49(10):e384. https://doi.org/10.1038/emm.2017.194.

[21] Naderi A, Zagatto AM, Akbari F, et al. Body composition and lipid profile of regular recreational table tennis participants: a cross-sectional study of older adult men. Sport Sci Health 2018;14(2):265-74. https://doi.org/10.1007/s11332-017-0422-1.

[22] Willems TM, De Ridder R, Roosen P. The effect of a long-distance run on plantar pressure distribution during running. Gait Posture 2012;35(3):405-9.

[23] Yan SH, Zhang K, Tan GQ, et al. Effects of obesity on dynamic plantar pressure distribution in Chinese prepubescent children during walking. Gait Posture 2013;37(1):37-42. https://doi.org/10.1016/j.gaitpost.2012.05.018.

[24] Butterworth PA, Urquhart DM, Landorf KB, et al. Foot posture, range of motion and plantar pressure characteristics in obese and non-obese individuals. Gait Posture 2015;41(2):465-9. https://doi.org/10.1016/j.gaitpost.2014.11.010.

[25] Song J, Kane R, Tango DN, et al. Effects of weight loss on foot structure and function in obese adults: a pilot randomized controlled trial. Gait Posture 2015;41(1):86-92. https://doi.org/10.1016/j.gaitpost.2014.08.013.

[26] Zhao X, Tsujimoto T, Kim B, et al. Does weight reduction affect foot structure and the strength of the muscles that move the ankle in obese Japanese adults? J Foot Ankle Surgery 2017;57(2):281-4. https://doi.org/10.1053/j.jfas.2017.09.010.

[27] De Cock A, De Clercq D, Willems T, et al. Temporal characteristics of foot roll-over during barefoot jogging: reference data for young adults. Gait Posture 2005;21(4):432-9. https://doi.org/10.1016/j.gaitpost.2004.05.004.

[28] Chang HW, Chieh HF, Lin CJ, et al. The relationships between foot arch volumes and dynamic plantar pressure during midstance of walking in preschool children. PloS one 2014;9(4):e94535. https://doi.org/10.1371/journal.pone.0094535.

[29] Cavanagh PR, Rodgers MM. The arch index: a useful measure from footprints. Journal Biomech 1987;20(5):547-51. https://doi.org/10.1016/0021-9290(87) 90255-7.

[30] Aydoğ E, Aydoğ ST, Çakci A, et al. Reliability of isokinetic ankle inversion-and eversion-strength measurement in neutral foot position, using the Biodex dynamometer. Knee Surgery, Sports Traumatology, Arthroscopy 2004;12(5):478-81. https://doi.org/10.1007/s00167-004-0530-8.

[31] Luna NMS, Alonso AC, Brech GC, et al. Isokinetic analysis of ankle and ground reaction forces in runners and triathletes. Clinics 2012;67(9):1023-8. https://doi. 
org/10.6061/clinics/2012(09)07.

[32] Moore IS, Jones AM, Dixon SJ. Mechanisms for improved running economy in beginner runners. Med Sci Sports Exercise 2012;44(9):1756-63. https://doi.org/10. 1249/MSS.0b013e318255a727.

[33] Nunns M, House C, Fallowfield J, et al. Biomechanical characteristics of barefoot footstrike modalities. Journal Biomech 2013;46(15):2603-10. https://doi.org/10. 1016/j.jbiomech.2013.08.009.

[34] Lee J, Hong YNG, Shin CS. The alteration in the center of pressure and duration ratio of stance sub-phases during upslope walking. Int J Precis Eng Manuf 2018;19(2):309-14. https://doi.org/10.1007/s12541-018-0038-7.

[35] Ferris L, Sharkey N, Smith T, et al. Influence of extrinsic plantar flexors on forefoot loading during heel rise. Foot Ankle Int 1995;16(8):464. https://doi.org/10.1177/ 107110079501600802.

[36] Nagel A, Fernholz F, Kibele C, et al. Long distance running increases plantar pressures beneath the metatarsal heads: a barefoot walking investigation of 200 marathon runners. Gait Posture 2008;27(1):152-5. https://doi.org/10.1016/j. gaitpost.2006.12.012.

[37] Karagounis P, Prionas G, Armenis E, et al. The impact of the Spartathlon ultramarathon race on athletes' plantar pressure patterns. Foot Ankle Specialist 2009;2(4):173-8. https://doi.org/10.1177/1938640009342894.

[38] Nachbauer W, Nigg BM. Effects of arch height of the foot on ground reaction forces in running. Med Sci Sports Exercise 1992;24(11):1264-9. https://doi.org/10.1249/ 00005768-199211000-00011.

[39] Gray H, Pick TP, Howden R. Anatomy, Descriptive and Surgical: Bounty Books New York. 1901.

[40] Basmajian JV, Stecko G. The role of muscles in arch support of the foot: an electromyographic study. JBJS 1963:45(6):1184-90.

[41] Fourchet F, Horobeanu C, Loepelt H, et al. Foot, ankle, and lower leg injuries in young male track and field athletes. Int J Athl Ther Train 2011;16(3):19-23. https://doi.org/10.1123/ijatt.16.3.19.

[42] Basmajian JV, Stecko G. The role of muscles in arch support of the foot: an electromyographic study. J Bone Joint Surg 1963;45(6):1184-90. https://doi.org/10. 2106/00004623-196345060-00006.

[43] McPoil TG, Cornwall MW, Dupuis L, et al. Variability of plantar pressure data. A comparison of the two-step and midgait methods. J Am Podiatric Med. Assoc 1999;89(10):495-501. https://doi.org/10.7547/87507315-89-10-495. 